\title{
A Hybrid Approach to Thematic Analysis in \\ Qualitative Research: Using a Practical
}

\section{Example}

\author{
Jon Swain \\ University College London, UK
}

\section{Discipline}

Sociology [D1]

\section{Sub-discipline}

Sociology of Education [SD-Soc-12]

\section{Academic Level}

Postgraduate

\section{Contributor Biography}

Jon Swain currently works at University College London where he is a senior researcher and lecturer. He mainly carries out qualitative research, which has included a series of numeracy and literacy projects in the post-16 sector. He has also written many articles on boys' masculinities. Between 2008 and 2013, he was program leader for the MPhil/PhD; he also has extensive 
teaching experience on the EdD program and continues to supervise and tutor both $\mathrm{PhD}$ and $\mathrm{EdD}$ students. His professional career began as a primary school teacher, and he took a part-time MA at the Institute of Education in the late 1990s before completing his $\mathrm{PhD}$ in 2001.

\section{Abstract}

Building on previous literature in the field of qualitative analysis, this case presents a flexible framework for using a form of thematic analysis employing a hybrid approach of deductive and inductive reasoning. The analysis is based on 25 semi-structured interviews from a real-life, qualitative, study about people's attitudes toward retirement and their expectations of growing older. This case also provides details of actual codings, examples of interview data, which are organized in a Microsoft Word document, and a table (or spreadsheet) that is an integral constituent of the analysis. The process is organized in three phases, containing seven stages in total, many of which can be concurrent and followed in any order. The analysis is viewed as being ongoing, organic, and iterative, requiring the researcher to be reflective and reflexive.

\section{Learning Outcomes}

By the end of this case, students should be able to

- Understand more about using thematic analysis in qualitative research

- Apply a specific hybrid approach to using thematic analysis

- Appreciate the number of decisions that the researcher needs to make when conducting qualitative analysis

\section{Case Study}




\section{Introduction}

Although researchers in the social sciences often include intricate accounts of the methods they have used and present detailed accounts of the findings from their investigations, the process of analysis is frequently one of the least discussed parts of the research procedure. Centered on a recently completed study, this case sets out a framework for using a form of one of the most widely used methods of analysis - thematic analysis — which, in this case, uses a particular hybrid approach involving deductive and inductive reasoning.

There has been a good deal of literature on the subject of thematic analysis over the past two decades (e.g. see Boyatzis, 1998; Braun \& Clarke, 2006, 2013; Clarke \& Braun, 2013; Fereday \& Muir-Cochrane, 2006; Guest et al., 2012; Joffe, 2011), and the focus of Jennifer Fereday and Eimear Muir-Cochrane's article is specifically on using a hybrid methodology. Much of the writing is practical, providing step-by-step guides to assist masters and doctoral students, and indeed professional researchers, in their own analysis of qualitative data, although some people choose to use the guides more loosely, and less prescriptively, than others.

The aim of this case is to provide guidance on how to use a particular form of thematic analysis, and although it builds on the influential work cited in the previous paragraph, there are a number of significant differences. For instance, rather than set out a detailed linear procedure, I present an overarching flexible framework, and although I delineate a number of specific stages, many of these can happen concurrently, rather than sequentially. The process of analysis is viewed as ongoing, organic, and iterative, and the researcher needs to be reflective and reflexive. I base the analysis on a real-life project about people's attitudes to retirement and their expectations of growing older, which used interviews as its main research method. Unlike many 
of the other guides, I also provide details of actual codings that I used, examples of interview data, which are organized in a Microsoft Word document, and present a table or spreadsheet that is an integral constituent of the analysis.

I begin with a definition of thematic analysis, followed by a brief introduction to the research study, which I am using as a vehicle on which to base the method of analysis. The main part of this case outlines the process of analysis I used, which can be employed as a tool by teachers, students, and researchers. The case concludes with an evaluation of the method and considers how it can also be used with CAQDAS (computer-assisted qualitative data analysis).

\section{Thematic Analysis}

Qualitative methods of analysis can be notoriously varied and complex (Holloway \& Todres, $\underline{2003}$ ), and Harry Wolcott (1994) points out that there are at least 50 distinct types of analysis to choose from, including content analysis, interpretative phenomenological analysis, template analysis, discourse analysis, narrative analysis, and conversation analysis. It can appear a daunting task to try to make sense of what can seem like an overwhelming amount of data and transform into a readable form (Wolcott, 1994). Although there are a number of textbooks about qualitative analysis (e.g., Given, 2008; Grbich, 2006; Ritchie et al., 2013), which provide a number of articulations of the process, the basic principle of qualitative analysis is summarized by Matthew Miles and Michael Huberman, who describe the three concurrent "flows of activity," which all analyses need to follow (Miles \& Huberman, 1994, p. 12): that is, data reduction, data display, and conclusion drawing. 
Thematic analysis is the most widely used qualitative analytic method in the social sciences across a range of disciplines, such as sociology, anthropology, and psychology. Virginia Braun and Victoria Clarke (2006) maintain that thematic analysis is the first qualitative method of analysis that researchers should learn as it provides a set of foundational, core techniques and skills that are used in many other forms of qualitative analysis, some of which have already been mentioned. Braun and Clarke also argue that thematic analysis provides a great deal of flexibility and can be applied across different epistemological and ontological positions.

Fereday and Muir-Cochrane (2006) describe thematic analysis as being "a search for themes that emerge as being important to the description of the phenomenon" (p. 82). It is a method, or process, for identifying and encoding patterns of meaning in primary qualitative research (Braun \& Clarke, 2006, 2013); it pinpoints and organizes the themes which the analyst deems to be important in the description of the phenomenon under study and are often associated with a specific research question (Daly et al., 1997).

\section{Details of the Study That I Am Using to Illustrate the}

\section{Method}

This particular method of analysis is based on a project that I have recently completed, which was about people's attitudes toward retirement and their feeling toward old age (hence known as "the retirement study"). I use this research purely as an example to demonstrate the process of analysis that I set out in this case, but it could be one of many, relatively small, qualitative research studies that I have worked on over the past 15 years. 
This particular study actually used mixed methods and the qualitative element (Creswell, 2007), which forms the basis of this case, involved carrying out a series of in-depth individual interviews with 25 people. Although they included a mixture of women and men, living in a variety of family circumstances, all the participants were approaching 60 years old, were White British, and were in either full-time or part-time employment.

As a sociologist, I am interested in human relations and practices and how they make meanings. The epistemological approach to the study was informed by Alfred Schutz's $\underline{(1970)}$ theory of social phenomenology, which is "an interpretive theory of social action that explores the subjective experience within the taken-for-granted, 'commonsense' world of the daily life of individuals" (Fereday \& Muir-Cochrane, 2006, p. 81). The underlying assumption of the theory is that in the lived reality of daily life people are able to attribute meanings to situations and make a series of judgments. The primary objective of the data collection was to represent the subjective viewpoints of the participants on a range of issues.

The interviews were semi-structured (Cohen et al., 2011; Robson, 2011), which is a commonly used method in qualitative research that not only provides a framework but also gives the interviewer the flexibility to probe on certain issues with more open and follow-up questions. So, although the interviews were relatively structured in that there were a designated series of main questions that every interviewee was asked to respond to, the questions were not necessarily asked in a same order and individuals were also encouraged to talk about, and elaborate on, other connected areas if they felt inclined to do so.

The schedule was divided into eight areas of enquiry, and these narrative accounts lasted, on average, around 90 minutes. In addition to asking questions about their attitudes toward, and 
expectations of, retirement and their feeling of getting older, the questions also gathered demographic information and data on interviewees' general health, history of employment (including their current job), leisure interests, caring responsibilities, and their financial situation. All the conversations were digitally recorded and transcribed.

\section{A Hybrid Approach to Analysis}

The method of analysis that I used was a hybrid approach that incorporated the two main contrasting philosophical methods of reasoning: a top-down, deductive, theoretical process and a bottom-up, inductive, data-driven process. ${ }^{1}$ The former produced a set of a priori (or preempirical) codes (similar to the work of Crabtree \& Miller, 1999) that came from the research aims, research questions, and individual questions asked in the interviews, whereas the latter approach, based on the work of Barney Glaser and Anselm Strauss (1967; see also Charmaz, 2006) and more recently re-formulated by Richard Boyatzis (1998), resulted in a series a posteriori (post-empirical, or after the fieldwork) codes derived from an examination of data generated. This means that theory was both a precursor to, and an outcome of, the data analysis.

There is an epistemological and ontological difference in coding from deductive and inductive approaches. Researchers using deductive methodologies tend to draw on more positive epistemologies, which regard data as "pre-existing" or "ready-made" forms of evidence in an external reality, and so use the term "collecting data." In contrast, those working with inductive methodologies use social constructivist and interpretive epistemologies that emphasize the emergent properties of the researcher working in a social setting where data have "yet to be discovered," and therefore say they are "generating data" or "developing" them from new. 
The researcher is not neutral: the position they take comes from their role as an agent interpreting the "thing(s)" they find in the world, in their reality. The researcher acts as a mediator, influencing data/findings, by constantly making choices and selections on how and what to code, and how and why data/findings are presented and re-presented.

One of the criticisms of thematic analysis by Braun and Clarke (2006) is that it can be "poorly demarcated" (p. 5), although this is hardly the preserve of only this particular method. Like all forms of analysis, thematic analysis needs to be rigorous, and it is important to make the process as visible, or transparent, as possible so that the reader can follow and appraise how it was carried out. Although the thematic approach that I am advocating herein is flexible, I am still arguing that it is systematic; the trail of evidence presented should help to demonstrate not only the credibility and veracity (Koch, 1994) of the process but also its competence.

The analysis set out in this case contains a major element of inductive methodology, but this was not reflected in the fieldwork as almost all of the interview questions were created before the interviews commenced; after five pilot interviews, the questions were fixed and designed to complement the quantitative questions and explore them in greater depth. The schedules contained around 70 questions, although there were many prompts to other areas, and, as I have mentioned earlier, interviewees were encouraged to talk more about these if they wished to. In the main, though, as the sequence of interviews progressed, they did not begin to throw up new questions, or create lines of enquiry, that were then incorporated into the schedules.

One of the main differences between the analysis I outline herein and other, more conventional methods of thematic analysis, is that I do not differentiate between a code and a 
theme. Boyatzis (1998) describes a "good code" as something that captures the qualitative richness of the phenomenon (p. 1), although I am not sure this is particularly helpful. I see a code at its most basic as being something that seems of interest to the researcher, which they think might help them answer their question or problem. In an interview transcript, this might be a word, phrase, sentence, or even a paragraph that relates to a phenomenon, and thus becomes an analytic unit of meaning that the researcher denotes (or records) with a word or simple term.

There has been some discussion in the literature about what the difference is between a code and a theme. Often a code is seen as something shorter, more succinct, or basic, whereas themes are usually expressed in a greater number of words and are seen as being "broader" (Braun \& Clarke, 2006, p. 18). Fereday and Muir-Cochrane (2006) contend that a number of codes can be connected together to form a theme, whereas Boyatzis (1998) defines a theme as "a pattern in the information that at minimum describes and organises the possible observations and at maximum interprets aspects of the phenomenon" (p. 161). However, are not codes all about interpretation as well? When I carry out analysis, I often find it difficult to distinguish between the two terms and tend to use them interchangeably. After all, I might begin by coding a phrase or sentence as being about "retirement," but surely this is also a large and significant concept, and so should I call it a theme? In the end, I have found that the distinction between a code and a theme is relatively unimportant and I therefore refer to these units of meaning as either "codes/themes," but usually as just "codes,"2 even though this can sound a little perverse in a method that is called thematic analysis.

\section{Three Phases and Seven Stages of Analysis}


The process of analysis that I am proposing, and which I used to analyze the retirement study data, is organized under three phases, which contains a total of seven stages. These are presented in a simplified form in Figure 1. They can begin as soon as the first interview transcripts are completed and are made available for interrogation.

\section{Figure 1.}

Caption: The three phases and seven stages of analysis.

Although the three phases need to be followed sequentially, the stages within each phase do not, and each stage can be taken in any order and can happen concurrently. For example, in Phase 1, you may choose to begin by familiarizing yourself with interview data (Stage 3) before you prepare the table ${ }^{3}$ it is up to you. Or you may decide to begin the process of analysis by creating a list of a priori codes (Stage 2) from the aims of the study, from the research questions, and, in the case of the study described earlier, from the interview questions. I could do this as I knew I was going to find codes on, for example, retirement, old age, health, leisure, and jobs.

After completing Stages 4 and 5 in Phase 2, you will finally move on to Stages 6 and 7 in Phase 3. The process is organic, iterative, and ongoing and requires the researcher to be reflexive. I will now look at the stages in more detail and provide some actual examples taken from the study.

\section{Phase 1}

Stage 1: Prepare a Table of the Codes and Information 
The table is to be used to record the codes and summarize responses against each participant. I generally write the names of participants along the top, horizontal (or $x$ axis) and have information and codes down the side, that is the vertical (or $y$ axis), but there is no hard rule about this. In the retirement study, I interviewed 25 people, but, due to considerations of space, only three are shown in the example in Table 1 (and later in Table 2).

\section{Table 1.}

Caption: The table with codes and information.

\begin{tabular}{|l|l|l|l|}
\hline & Name (interview 1) & Name (interview 2) & Name (interview 3) \\
\hline A priori codes & & & \\
and a posteriori & & & \\
codes (in italics) & & & \\
\hline
\end{tabular}

Stage 2: Create A Priori Codes

The next stage involves creating a priori codes based on the research aims and research questions, including interview questions. If I had used another method, such as observations, I would have based the a priori codes on these. In the case of the retirement study, the demographic information that I collected was the easiest to code: that is, the participants' gender, whether or not they had a partner, whether or not their parents were alive, whether they had children, or whether they owned their own home or lived in rented accommodation.

Altogether, I found 20 a priori codes: 


\begin{tabular}{|l|}
\hline A priori codes \\
Gender \\
Children \\
Partner \\
Parents \\
Accommodation \\
Physical health \\
Mental health \\
Past job(s) \\
Current job \\
Leisure activities \\
Amount of free time \\
Retirement feels near \\
Retirement feels far away
\end{tabular}


Caring for younger people

Has enough money for retirement

Saving

Stage 3: Begin to Familiarize Yourself With the Data

I then began by acquainting (or re-acquainting) myself with interview data, and as noted earlier, I could have made this Stage 1. There were actually three researchers working on the project and carrying out the interviews, and although I took responsibility for analyzing these data, I only interviewed 14 of the 25 participants. So while I could remember quite a lot of what that people said from my own interviews, I was unfamiliar with data from the other 11.

Before I started any coding, I began to read through one or two interviews to familiarize myself with the data and get a sense of how rich they were going to be.

\section{Phase 2}

Stage 1: Begin A Priori and A Posteriori Coding (Creating A Posteriori Codes As You Go Along)

After the first three stages (which, remember, can be taken in any order), I began to search for meanings and patterns in the conversations, and both apply the a priori codes and create a new series of a posteriori codes. In general, this will be an ongoing process and will continue until all the interview transcripts have been read through. After reading the first one or two transcripts, you will probably have only a small number of a posteriori codes, but this number will grow as you read on. When I was coding in this way, I only had about nine of these codes after the first interview, but I had 17 at the end of the 25 th interview. This meant that once I had completed the 
cycle, I needed to return to the early transcripts and read them through again to make sure I had not missed applying codes from the full set of 17. Thus, the analysis was circular.

The a posteriori codes are shown below, and I use italics as another way of distinguishing them from the a priori codes in the previous list. Sometimes you will find that you have more a priori than a posteriori codes (as in this case), but this depends on the type of research approach you are using. The more leanings it has toward positivistic methodologies (e.g., an experimental design), the more likely you will find that the number of a priori codes will dominate.

\begin{tabular}{l}
\hline A posteriori codes \\
Partner's health \\
Partner's death \\
Parents' health \\
Close group of friends \\
Early retirement \\
Haven't thought about retirement \\
Does not want to retire \\
Plans
\end{tabular}


Identity

Not feeling in control

Responsibilities

Possibility of downsizing home

Getting by with little money

Biggest financial regret

Stage 2: Begin and Continue to Add and Summarize Information From Interview

Transcripts Onto the Table

As I continued to read through and code the interview data, I also began to summarize interviewees' responses to particular questions. Once again, using the example of the retirement study, the easiest part was to summarize the demographic information, and questions around such topics as work and employment generally needed a slightly more expansive summary against the named participants. One great advantage of presenting the data in a table is that it provides an overall view and summary of all your participants at a glance and shows who they are/were and what they said in response to certain questions and about particular issues. Imagine if Table 2 (which shows the development of Table 1 as the data are added) displayed all 25 interviews: I could tell very quickly how many people had, for example, a partner or how many thought retirement was near or far away. And if I was using a spreadsheet, I could, if I wanted to, also set up filters to show, for example, how many women and how many men thought this was so.

Table 2. 
Caption: A priori and a posteriori codes and a summary of interview information.

\begin{tabular}{|c|c|c|c|}
\hline & Alison & Hannah & Andy \\
\hline \multicolumn{4}{|c|}{ A priori codes and a posteriori codes (in italics) } \\
\hline \multicolumn{4}{|l|}{ Demographics } \\
\hline Sex/gender & Female & Female & Male \\
\hline Has partner & Yes & Yes & No, divorced \\
\hline Partner's health & Good & Excellent & $\mathrm{n} / \mathrm{a}$ \\
\hline Parent(s) alive & Yes, both & Neither & Father yes, $\mathrm{m}$ \\
\hline Parent(s) health & Good, both in $80 \mathrm{~s}$ & $\mathrm{n} / \mathrm{a}$ & Father in hon \\
\hline Parent(s) death & $\mathrm{n} / \mathrm{a}$ & Both died in their $60 \mathrm{~s}$ & Mother died \\
\hline Has children & No & Yes, two both in their 20s & One son, age \\
\hline Owned or rented & Rented & $\begin{array}{l}\text { Own (mortgage almost paid } \\
\text { off) }\end{array}$ & Rented \\
\hline \multicolumn{4}{|l|}{ Health } \\
\hline Physical health & Good & Excellent & Poor \\
\hline Mental health & Very good & Excellent & Poor \\
\hline
\end{tabular}




\begin{tabular}{|c|c|c|c|}
\hline Work & & & \\
\hline History of work & $\begin{array}{l}\text { Had a variety of low-paid, } \\
\text { low-skilled, part-time jobs, } \\
\text { mainly in retail }\end{array}$ & $\begin{array}{l}\text { Had two main full-time } \\
\text { careers-as a primary school } \\
\text { teacher and as a lecturer in } \\
\text { further education }\end{array}$ & $\begin{array}{l}\text { Worked in fa } \\
\text { and as a secu } \\
\text { lengthy spells }\end{array}$ \\
\hline Current job & Part-time shop assistant & $\begin{array}{l}\text { Full-time lecture at local } \\
\text { further education college }\end{array}$ & Part-time sec \\
\hline Enjoyment of work & Not very much & $\begin{array}{l}\text { Yes, both jobs although } \\
\text { found primary teaching } \\
\text { stressful }\end{array}$ & $\begin{array}{l}\text { Has hated all } \\
\text { done }\end{array}$ \\
\hline \multicolumn{4}{|l|}{ Leisure } \\
\hline Main leisure & Watching TV, swimming & $\begin{array}{l}\text { Reading, walking, going out } \\
\text { for meals }\end{array}$ & $\begin{array}{l}\text { Volunteers in } \\
\text { listens to mus }\end{array}$ \\
\hline Amount of free & Not much & A fair amount & A lot \\
\hline $\begin{array}{l}\text { Has a close group } \\
\text { of friends to spend time with }\end{array}$ & Yes, around 5 & $\begin{array}{l}\text { Yes, regular set and has two } \\
\text { "best" friends }\end{array}$ & No \\
\hline
\end{tabular}

Retirement 


\begin{tabular}{|c|l|l|l|}
\hline Does retirement & Far & Far & Quite near as \\
he can only \\
week
\end{tabular}

Getting older 


\begin{tabular}{|l|l|l|l|}
\hline Main worries & Failing health and money & Health & Health and $\mathrm{m}$ \\
\hline Nontrol & Not asked & Feels in control of her life & Does not feel \\
\hline Identity & Not asked & Sees herself as still being & Thinks the be \\
& & young & are behind hi \\
\hline
\end{tabular}

Caring responsibilities

\begin{tabular}{|c|l|l|l|}
\hline For older people & $\begin{array}{l}\text { None, as both parents still } \\
\text { independent }\end{array}$ & None-parents both dead & Mother in a h \\
her regularly
\end{tabular}

Finance

\begin{tabular}{|c|c|c|c|}
\hline $\begin{array}{l}\text { Thinks they will } \\
\text { have enough money for their } \\
\text { retirement }\end{array}$ & $\begin{array}{l}\text { No, and will have to work } \\
\text { beyond } 66\end{array}$ & $\begin{array}{l}\text { Yes, has a work place } \\
\text { pension scheme }\end{array}$ & $\begin{array}{l}\text { Might do as } 1 \\
\text { rent paid by } t\end{array}$ \\
\hline Savings & Very little & $\begin{array}{l}\text { Yes-see above plus various } \\
\text { shares }\end{array}$ & None \\
\hline Has the opportunity & Not an option as currently & Yes, but want to stay where & Not an optior \\
\hline
\end{tabular}




\begin{tabular}{|c|l|l|l|}
\hline to move to a smaller home & in rented accommodation & she is & rented accom \\
\hline $\begin{array}{c}\text { Thinks they will be } \\
\text { retirement }\end{array}$ & Not really, likes to spend & No, wants to retire and & Yes, probably \\
\hline Financial regrets & Never put money aside & Could have bought house & Didn't take o \\
\hline
\end{tabular}

You will notice in Table 2 that some participants were not asked, or did not expand on, some areas of enquiry. This sometimes happens when interviews are semi-structured or unstructured and is particularly the case when interviewees are given the chance to have extended conversations about a particular topic or issue, and these responses are more likely to have a posteriori codes. Furthermore, there are a number of cells where the response is not applicable (n/a) to the individual participant.

\section{Phase 3}

\section{Stage 1: Cut and Paste Interview Text Into Microsoft Word Document}

As I read through the interviews, I highlighted sections of text next to each code and cut and pasted the text into a Microsoft Word document. These excerpts are chosen on the basis of the interviewee saying something particular illustrative of a point or argument that you think you will want to make in your report. The headings, which align to both sets of codes, can be prepared in advance, but it is essential to give each interview a number for identification purposes. Figure 2 shows an example of data, which I cut and pasted based on the question, "Does retirement feel near or far away?" 


\section{Figure 2.}

Caption: Extracts of data from interview from the code of "Retirement Feels Near or Far Away."

Sometimes, many extracts have more than one code. We can see in Figure 2 that I have actually combined two a priori codes_- "retirement is near" and "retirement is far away"_into one, but these extracts will often contain more than one code, and some are likely to contain multiple codes, sometimes within one sentence. I am not carrying out discourse analysis or conversational analysis, where every word, pause, and intonation count. Rather, my focus is on the broad sense of the meanings people are conveying through words, phrases, and sentences, so I am coding chunks of text in a relatively broad and contextual fashion. In computer software data analysis packages, such as NVivo, different codes within the same extract can be shown by using a number of (colored) coding stripes. In Figure 2, I have underlined words and phrases to show the use of both further a priori codes and new posteriori codes that arose from the data. These were then added to the list down the side of the table as the process of coding progressed. Taking, first, the example of Interview 5, there was an additional a priori (or pre-empirical) code of "caring for older people" (added to the main a priori code of "Retirement, feels near or far away") and four new a posteriori (post-empirical) codes of "early retirement," "triggers," "parents' health" and "responsibilities." In Interview 9, there were further new a posteriori codes of "options" and "responsibilities," which comes from my interpretation of the interviewee saying he needs to keep working to look after his family.

\section{Stage 2: Collapse the A Priori and A Posteriori Codes Into Family Codes}

Once you have finished reading through and coding the interviews, you will usually find that you have an extensive list of both a priori and a posteriori codes, and in the examples that I have been 
using, this came to a total of 37 codes. Because this was a rather unmanageable number, the next stage before I could begin to write up my findings was to merge or collapse these codes into families, which are of a more manageable size and can then be used to structure the findings in the report.

The following list shows the eight family codes that I used in the retirement study. Many of the family codes are similar to the main areas of enquiry that were investigated, and as they are more likely to have derived from the a priori set of codes, they can look a bit circular. However, this is not inevitable, and indeed, some of my family codes derived from a posteriori codes, which in the following example are on friendship, identity and agency.

\begin{tabular}{|l|}
\hline Family codes \\
\hline Health \\
\hline Work \\
\hline Friendship \\
\hline Retirement \\
\hline Old age \\
\hline Financial situation \\
\hline Identity \\
\hline Agency \\
\hline
\end{tabular}


Because these family codes are actually a series of interconnected codes, I could easily agree with Fereday and Muir-Cochrane (2006) and call them family themes, but as I have written before, I see the distinction between a code and theme as being essentially semantic rather than conceptual.

\section{Conclusion}

This case has delineated a flexible process of a particular form of thematic analysis, which uses a hybrid approach involving deductive and inductive reasoning. The most important decision to make in the whole analytical process is to choose a method that is congruent to your methodology and is the one most appropriate to answer your research questions. Thus, if you are interested in investigating how verbal and non-verbal conduct and procedures are organized in different contexts of everyday life, you will probably employ conversation rather than thematic analysis.

Although I have based this exposition on a recently completed study in which the main method used was the semi-structured interview, the model can be used for other methods of data collection and generation, such as observation and video analysis.

The method is particularly suitable for relatively small qualitative research studies, where the information can be summarized and overviewed on a simple table, and I usually only tend to use this approach when I have conducted fewer than 30 interviews. However, I recognize that this is an arbitrary number and will depend on the length and complexity of the interviews. When I carried out the analysis for my $\mathrm{PhD}$ (with over 70 interviews), I used a computer software package and I would still recommend that software such as ATLAS.ti, NVivo, and Qualrus be 
used when data sets are more extensive and more complicated, and when the analysis needs to be more nuanced with more variables, intended, perhaps, for a doctoral thesis. This is not to say that computer software could not be used in the process I have outlined herein; it has many advantages, including being able to apply multi-codes to the same extract of data, and recall these extracts at the touch of a button. However, using a computer can make the analysis process a little mechanical, and I argue that it is also possible to carry out qualitative analysis without a computer in a simpler, and perhaps less complicated, way. Sometimes, as a professional researcher, I am asked to work on a project with a relatively small sample, analyze the data, and write a report in a comparatively short space of time, and the method I have described in this case is the one that I most commonly employ. I also meet many other students and researchers who are always comfortable with using CAQDAS, and I hope that this case provides all types of researchers with a choice of methods.

\section{Notes}

1 Another, less commonly used philosophical method in academic research is abductive reasoning, which seeks to find the simplest and most probable explanation. It is often associated with the kind of daily decision making that makes the best of the information available, which often is incomplete, and so has to come up with a best guess. A good example would be a medical diagnosis, which takes a set of symptoms and tries to provide the best explanation of them.

2 I will mainly use the term "code" on its own to signify code/theme for the rest of this case. 3 The use of the term "table" also denotes "spreadsheet," and for most of this case, the two words are used interchangeably. 


\section{Exercises and Discussion Questions}

1. What kinds of decisions do researchers need to make when carrying out thematic analysis?

2. What are the main differences between carrying out analysis that is based on deductive and inductive approaches?

3. What do you see as the main differences between a code and a theme? Is this a useful distinction?

4. What are the advantages and disadvantages in carrying out this particular form or hybrid thematic analysis?

5. Can you think of some other areas of enquiry that hybrid thematic analysis would be particularly suitable for?

6. Explain how you would use this hybrid approach in your own research? Could you make a list of what would your a priori codes be?

7. To what extent does carrying out qualitative analysis rely on the researcher's own interpretations and subjectivity? How does this affect that validity of the findings?

8. If two or more researchers used this approach with the same data set, how similar do you think their findings would match? Argue both for them being alike and different.

\section{Further Reading}

Carpenter, C., \& Suto, M. (2008). Qualitative research for occupational and physical therapists: A practical guide. Oxford, UK: Blackwell.

Crotty, M. (1998). The foundations of social research. Crows Nest, Australia: Allen \& Unwin. 
Rice, P., \& Ezzy, D. (1999). Qualitative research methods: A health focus. Melbourne, Australia: Oxford University Press.

\section{References}

Boyatzis, R. E. (1998). Transforming qualitative information. Cleveland, OH: SAGE.

Braun, V., \& Clarke, V. (2006). Using thematic analysis in psychology. Qualitative Research in Psychology, 3, 77-101.

Braun, V., \& Clarke, V. (2013). Successful qualitative research: A practical guide for beginners. London, England: SAGE.

Charmaz, K. (2006). Constructing grounded theory: A practical guide through qualitative analysis. London, England: SAGE.

Clarke, V., \& Braun, V. (2013). Teaching thematic analysis: Overcoming challenges and developing strategies for effective learning. The Psychologist, 26, 120-123.

Cohen, L., Manion, L., \& Morrison, K. (2011). Research methods in education (7th ed.). New York, NY: Routledge.

Crabtree, B., \& Miller, W. (1999). A template approach to text analysis: Developing and using codebooks. In B. Crabtree \& W. Miller (Eds.), Doing qualitative research (pp. 163-177). Newbury Park, CA: SAGE. 
Creswell, J. W. (2007). Qualitative inquiry and research method: Choosing among five approaches (2nd ed.). Thousand Oaks, CA: SAGE.

Daly, J., Kellehear, A., \& Gliksman, M. (1997). The public health researcher: A methodological approach. Melbourne, Australia: Oxford University Press.

Fereday, J., \& Muir-Cochrane, E. (2006). Demonstrating rigor using thematic analysis: A hybrid approach of inductive and deductive coding and theme development. International Journal of Qualitative Methods, 5, 80-92.

Given, L. M. (2008). The Sage encyclopedia of qualitative research methods (Volumes 1 and 2). London, England: SAGE.

Glaser, B., \& Strauss, A. (1967). The discovery of grounded theory: Strategies for qualitative research. Mill Valley, CA: Sociology Press.

Grbich, C. (2006). Qualitative data analysis: An introduction. London, England: SAGE.

Guest, G., MacQueen, K. M., \& Namey, E. E. (2012). Applied thematic analysis. Thousand Oaks, CA: SAGE.

Holloway, I., \& Todres, L. (2003). The status of method: Flexibility, consistency and coherence. Qualitative Research, 3, 345-357.

Joffe, H. (2011). Thematic analysis. In D. Harper \& A. R. Thompson (Eds.), Qualitative methods in mental health and psychotherapy: A guide for students and practitioners (pp. 209-224). Chichester, UK: Wiley. 
Koch, T. (1994). Establishing rigour in qualitative research: The decision trail. Journal of Advanced Nursing, 19, 976-986.

Miles, M., \& Huberman, A. (1994). Qualitative data analysis. Thousand Oaks, CA: SAGE.

Ritchie, J., Lewis, J., McNaughton Nicholls, C., \& Ormston, R. (2013). Qualitative research practice a guide for social science students and researchers. London, England: SAGE.

Robson, C. (2011). Real world research (3rd ed.). Oxford, UK: Blackwell.

Schutz, A. (1970). On phenomenology and social relations: Selected writings (H. Wagner, Ed.). Chicago, IL: University of Chicago Press.

Wolcott, H. (1994). Transforming qualitative data: Descriptions, analysis and interpretation. London, England: SAGE. 